Revista Eletrônica Espaço Teológico ISSN 2177-952X. Vol. 12, n. 22, jul/dez, 2018, p. 54-62

\title{
NOSSA SENHORA DA CONCEIÇÃO APARECIDA: UM SINAL DE MARIA NA PERSPECTIVA DO MISTÉRIO DA IGREJA
}

(Our Lady of the Conception Aparecida: a signal

of Mary in the perspective of the Church's mistery)

\begin{abstract}
Anderson Adevaldo dos Santos
Mestrando em Teologia Sistemática pela Pontifícia Universidade Católica de São Paulo (PUC/SP)

E-mail: ander.as@gmail.com
\end{abstract}

\section{RESUMO}

O objetivo desta comunicação, realizada no dia 18 de maio de 2018, no Santuário Nacional de Aparecida, durante o XII Congresso Mariológico, é apresentar uma "restauração teológica" da imagem de Nossa Senhora da Conceição Aparecida, numa perspectiva eclesiológica, a partir de uma releitura simbólica, bíblica e pastoral dos elementos presentes no encontro da sua imagem e no significado da própria imagem em si, a fim de que, por meio da sua iconografia, possamos extrair uma mensagem significativa acerca do mistério da Igreja que tem a Virgem Maria como Mãe, Membro e Modelo.

Palavras-chave: Aparecida; Imagem; Sinal; Mistério; Igreja; Maria.

\begin{abstract}
The purpose of this communication, written on May 18th, 2018 at the National Shrine of Aparecida, during the XII Mariologycal Congress, is to present a "theological restoration" of the image of Our Lady of the Conception Aparecida, through an ecclesiological perspective, from a symbolic, biblical and pastoral re-reading, of the elements present in the found of its image and the meaning of the image itself, in order to, by its iconography, extract a significant message about the mystery of the Church that has the Virgin Mary as Mother, Member and Model.
\end{abstract}

Keywords: Aparecida; Image; Signal; Mystery; Church; Mary.

\section{INTRODUÇÃO}

Por ocasião do Ano Mariano Nacional (2017), que a Igreja do Brasil há pouco tempo celebrou para comemorar o Jubileu dos 300 anos de Aparecida e, no transcurso das comemorações dos 40 anos da restauração da imagem de Nossa Senhora da Conceição Aparecida (1978-2018), o presente artigo procura apresentar uma reflexão teológica, sobretudo eclesial, a partir do seu contexto histórico de origem e das características de sua própria imagem. 
Revista Eletrônica Espaço Teológico ISSN 2177-952X. Vol. 12, n. 22, jul/dez, 2018, p. 54-62

Quando esteve no Rio de Janeiro, por ocasião da $28^{a}$ Jornada Mundial da Juventude, o Papa Francisco, pouco antes de se encontrar com jovens do mundo inteiro, por iniciativa pessoal, fez questão de visitar o Santuário Nacional de Aparecida. E durante o encontro com o episcopado brasileiro, em 27 de julho de 2013, apresentou o contexto histórico do encontro, a "pesca milagrosa", e a própria imagem de Nossa Senhora da Conceição Aparecida como "chave de leitura para a missão da Igreja", segundo a linguagem do "mistério". Disse o Papa que em Aparecida, "Há algo de perene para aprender sobre Deus e sobre a Igreja"1.

Por isso, a partir dessas palavras do Papa, o principal objetivo aqui visa a oferecer um sentido teológico ao evento e à imagem de Aparecida, a fim de não restringi-lo a um aspecto histórico ou a uma devoção superficial, mas a partir de uma nova miragem, contemplá-lo, compreendêlo e assumi-lo segundo a dimensão mariana da Igreja, para a qual a Virgem Maria é membro, mãe e modelo.

Em linhas gerais e segundo a "gramática da simplicidade", com a qual o Papa Francisco sugere que seja "pescado" o mistério de Deus e da Igreja revelado em Aparecida ${ }^{2}$, esta reflexão tem como pressupostos iniciais o contexto do Brasil colonial do século XVIII e da devoção mariana já existente e bem difundida em nosso país, seguida de uma hermenêutica bíblica e patrística de Apocalipse 12,1 para, finalmente, contemplar, em Nossa Senhora da Conceição Aparecida, uma imagem do mistério, da vida e da missão da Igreja.

\section{ASPECTOS HISTÓRICOS DO ENCONTRO DA IMAGEM DE NOSSA SENHORA DA CONCEIÇÃO APARECIDA}

A origem da imagem e da devoção a Nossa Senhora da Conceição Aparecida é uma narrativa simples e encantadora. $\mathrm{Na}$ "inútil labuta dos três pescadores buscando o peixe nas águas do Paraiba, naquele longínquo 1717", no "inesperado encontro do corpo e depois da cabeça da pequena imagem de cerâmica enegrecida pelo lodo", na "pesca abundante que se seguiu ao achado", no "culto, logo iniciado, a Nossa Senhora da Conceição sob as aparências daquela estátua trigueira, carinhosamente chamada a "Aparecida"'3, enfim, na simplicidade desta história, quando lida com "religiosa atenção", percebemos que há ali um sinal do mistério de Deus a ser revelado...

O encontro da imagem de Nossa Senhora da Conceição Aparecida é uma "história sagrada" surgida em meio a uma "história profana"4 que aconteceu no conturbado século XVIII, durante um período histórico conflituoso e tenso em termos antropológico, étnico, social, eclesial, político e econômico em nosso país, na época, colônia de Portugal.

Na gênese do encontro da imagem de Nossa Senhora da Conceição estava:

- o contexto econômico da "corrida do ouro" que, apesar de toda riqueza e prosperidade que proporcionou a alguns poucos, provocou disputas violentas e

\footnotetext{
${ }^{1}$ FRANCISCO, Discurso ao episcopado brasileiro, 27.07.2013.

${ }^{2}$ Cf. Ibidem.

3 JOÃO PAULO II. Homilia na Basílica de Aparecida, 4.07.1980.

4 Cf. DOMEZI, M. C. 300 anos de Aparecida: abordagem histórica. O contexto da aparição e a devoção popular, 2017, p. 180.
} 
Revista Eletrônica Espaço Teológico ISSN 2177-952X. Vol. 12, n. 22, jul/dez, 2018, p. 54-62

sangrentas entre nativos e estrangeiros, a chamada "Guerra dos Emboabas" (1708-09) e também, paradoxalmente, fome e miséria nas regiões auríferas das Minas e nas localidades próximas da "rota do ouro" entre São Vicente e Vila Rica, no caminho que corta o Vale do Paraíba;

- o contexto social da formação do povo brasileiro, desde o princípio aberto à pluralidade e a mestiçagem, ainda que não tenham faltado disputas entre os povos aqui nascidos e chegados, principalmente indígenas, colonizadores portugueses e seus descendentes, e negros traficados da costa africana;

- o contexto antropológico e social da escravidão negra, que deflagrava uma situação desumana e tragicamente social desde os meados do século XVI até praticamente o final do século XVIII, sendo o Brasil um dos últimos países a abolir a escravatura, o que aconteceu somente no século seguinte;

- o contexto religioso de um catolicismo popular e devocional do propagado culto mariano no Brasil, desde a chegada dos colonizadores, sob os mais variados títulos e invocações, entre os quais se destacava a Padroeira do Império português e de suas possessões, Nossa Senhora da Conceição;

- o contexto local da passagem de um Conde truculento na Vila de Guaratinguetá que, por meio da repressão, veio a pacificar os conflitos e a reestabelecer a ordem nas zonas mineradoras para garantir os interesses econômicos da Coroa.

É neste contexto do Brasil Colônia do início do século XVIII que surge, então, das águas de um rio, na rede de três pescadores, uma imagem de Nossa Senhora da Conceição com aproximadamente 38 centímetros, de estilo barroco e de forma murilesca; uma imagem de barro paulista escondido sob uma pátina morena, um "castanho brilhante" ou canelado pela ação do tempo e do uso que a despiu de sua policromia original, feita provavelmente na primeira metade de 1600 pelas mãos habilidosas do beneditino Agostinho de Jesus $(+1661)^{5}$.

Encontrada num "M" da curva de um rio brasileiro, a imagem de Nossa Senhora da Conceição, uma devoção já bastante difundida, mas com um novo significado em Aparecida, "apareceu" de modo misterioso na encruzilhada do Brasil colonial. "Deus aparece nos cruzamentos"6, nos sinais simples das vicissitudes humanas e históricas. O homem que procura o mistério de Deus poderá encontrá-Lo nas vicissitudes, nos ritmos e nos tempos da história humana, em meio às coisas do cotidiano e, especialmente, entre os simples, os pobres e os humildes. O contexto do encontro da imagem aparecidense é um exemplo dessa manifestação divina escondida sob os véus da pobreza e da humildade.

Numa zona de cruzamento entre São Paulo e Minas Gerais, durante o período da extração do ouro no Brasil, enquanto o governador da Capitania de São Vicente, o futuro "Conde" de Assumar, visitava as regiões mineradoras e suas adjacências, a Virgem Maria se dignou

${ }^{5}$ Cf. RIBEIRO NETO, P. A. A imagem de N. Senhora Aparecida, 1970, p. 174-185.

${ }^{6}$ FRANCISCO. Encontro com o Episcopado Brasileiro, 27.07.2013. 


\section{Revista Eletrônica Espaço Teológico ISSN 2177-952X. Vol. 12, n. 22, jul/dez, 2018, p. 54-62}

"aparecer" na rede de três pobres pescadores que, com um barco frágil e redes decadentes enfrentavam a labuta, o cansaço e o desânimo pelo insucesso da pesca num rio "imprestável", numa circunstância de carências, de falta de recursos, de fracasso e falimento em que buscavam peixes, por ordem das autoridades da Vila de Guaratinguetá, para saciar o apetite de tão ilustre visitante. Mas, pela imagem de Nossa Senhora "salva" das águas, "Deus chegou de uma maneira nova, porque Deus é surpresa: uma imagem de barro frágil, escurecida pelas águas do rio, envelhecida também pelo tempo. Deus entra sempre pelas vestes da pequenez" $\mathrm{O}$ mistério torna-se, portanto, um sinal divino revelado na realidade humana. E para manifestar a sua ternura e compaixão para com o nosso povo, "Em Aparecida, Deus ofereceu ao Brasil a sua própria Mãe"8 e, no "sinal da mulher", ícone da Igreja Servidora, Mãe e Esposa, a Igreja como que assume o papel de Maria na história.

\section{O SINAL DA MULHER "APARECIDA"}

Desde o primeiro momento, pela boca dos pobres, pela simplicidade dos humildes que se deixam tocar e estremecer diante do mistério de Deus revelado através da Virgem Maria, aquela pequenina imagem morena de barro foi chamada carinhosamente de "Aparecida", não porque tenha sido espetacularmente contemplada numa visão celestial, nem porque tenha pronunciado alguma palavra de caráter revelatório, como noutras mariofanias ${ }^{9}$, mas encontrada nas redes de três pescadores, quis assim aparecer de maneira admirável e prodigiosa $^{10}$.

"Aparecida", apesar do título, não é a rigor uma aparição no sentido estrito do termo ${ }^{11}$. Segundo Murad: "Aparições de Maria são manifestações de sua pessoa viva, não de estátuas ou imagens" 12 . Mas interessante é o modo como estes homens simples interpretaram o fato, pois não disseram "pescamos (ou achamos/encontramos) uma imagem de Nossa Senhora da Conceição", mas repetiam: "Nossa Senhora da Conceição Aparecida", como se a própria Senhora tivesse tomado a iniciativa de "aparecer", pois "Não foram os pescadores que foram ao encontro da imagem da Virgem, mas foi ela que surgiu/apareceu ou ainda se deixou encontrar nas águas e nas redes deles em dois momentos significativos [corpo e cabeça]"13.

Para além de uma invocação popular e devocional, "Aparecida" é, de certo modo, um título bíblico que recorda Ap 12,1: "Um sinal grandioso apareceu no céu: uma Mulher vestida com o sol, tendo a lua sob os pés e sobre a cabeça uma coroa de doze estrelas". Segundo os Padres da Igreja, o texto bíblico de Apocalipse 12 é uma alusão exclusiva à Igreja, mas que, de modo secundário, pode-se admitir uma referência mariana ${ }^{14}$. A interpretação desse texto deixa entrever nesta "mulher" duas realidades que não são dicotômicas, mas complementares entre si: a Igreja e Maria. A iconografia definitiva da Imaculada Conceição, que é uma criação

\footnotetext{
${ }^{7}$ Ibidem.

8 Ibidem.

9 Como, por exemplo, em Guadalupe, Fátima e Lourdes, em que há uma mensagem explícita para os videntes. Mas em Aparecida não há visões nem palavras.

${ }^{10}$ Cf. PAULO VI. Mensagem ao Cardeal Motta, 1967.

11 LAURENTIN, R. Aparições, 1995, p. 116: “Chama-se de aparição a manifestação visível de um ser cuja visão naquele lugar ou naquele momento é inusitada e inexplicável segundo o curso natural das coisas".

12 MURAD, A. Visões e Aparições: Deus continua falando?, 1997, p. 19-20.

${ }^{13}$ DA SILVA, R. M. F. Guadalupe-Aparecida-Lourdes: três mariofanias, uma mesma mensagem 2014 , p. 41.

${ }^{14}$ Cf. IWASHITA, P. Maria e Iemanjá: análise de um sincretismo, 1991, p. 141.
} 
Revista Eletrônica Espaço Teológico ISSN 2177-952X. Vol. 12, n. 22, jul/dez, 2018, p. 54-62

barroca, ibérica e pós-tridentina, para traduzir imageticamente tão complexo e sublime mistério da concepção virginal de Maria, também se inspirou em Ap 12,1.

"Aparecida" é uma imagem de Nossa Senhora da Conceição com o acréscimo da invocação e/ou título "Aparecida", que está relacionada à circunstância histórica de como a imagem foi encontrada pelos pescadores. Desse modo, podemos intuir que o título e a imagem de Nossa Senhora da Conceição Aparecida, indiretamente, podem ser inspirados em Ap 12,1.

A partir das circunstâncias históricas, da intepretação bỉblica e da iconografia imaculista, podemos dizer que a imagem de Nossa Senhora da Conceição Aparecida é uma imagem de Maria, ícone da Igreja Virgem da Fé e Servidora da Palavra, da Igreja Mãe na fonte batismal e da Igreja Esposa da Esperança.

A imagem aparecidense como símbolo da Igreja Virgem, Mãe e Esposa, por meio da interpretação dos elementos naturais do barro, da água e do peixe que estão presentes no seu contexto de encontro em 1717, é um sinal da fé na fragilidade, do nosso compromisso batismal e de esperança em meio ao fracasso.

\section{A IMAGEM DE APARECIDA E O MISTÉRIO DA IGREJA}

O "sinal de Aparecida" contém uma mensagem evangélica, profética e eclesial importantes para a nossa realidade, embora seja tão misteriosa e silenciosa. Ainda que nenhuma novidade venha acrescentar ao que já fora revelado pela Escritura e pela Tradição e ensinado pelo Magistério da Igreja, ele vem "rememorar" e "perspectivar" alguns elementos fundamentais da nossa fé e vida cristã que, ao longo do tempo, correm o risco de ser deteriorados ou esquecidos e que precisam ser resgatados para o autêntico seguimento de Jesus Cristo e para o discipulado e missão eclesial. Noutras palavras, "Aparecida" é um apelo à conversão e uma proposta para tempos de crise, assim como afirmou o Papa João Paulo II no Centenário de Coroação de nossa Mãe, Rainha e Padroeira (1904-2004): "A história ensina que Maria é a verdadeira salvaguarda da fé; em cada crise, a Igreja reúne-se à volta d'Ela"15.

Considerada a abordagem histórica e bíblica do evento "Aparecida", contemplamos a sua imagem e mensagem, conforme a eclesiologia mariana do Concilio Vaticano II, numa dimensão que busca compreender algumas perspectivas do mistério, da vida e da missão da Igreja, pois aquela imagem pequena e morena, quebrada e restaurada, contém uma chave de leitura teológica para a Igreja e para cada fiel que, pela força do Batismo, é chamado a ser sinal de Cristo no mundo.

A imagem de Aparecida quer nos comunicar uma mensagem de unidade e comunhão. Como não há uma mensagem explícita, assim como numa aparição, a partir do contexto eclesial, da hermenêutica bíblica do "sinal da mulher" de Ap 12 e dos aspectos simbólicos da própria imagem, podemos perceber como cada detalhe da imagem aparecidense, bem como $o$ contexto de seu encontro, está carregado de uma mensagem de unidade e comunhão que a Virgem Maria, mulher-ícone do mistério da Igreja, quer nos recordar na sua imagem "Aparecida":

${ }^{15}$ JOÃO PAULO II. Carta ao Cardeal Damasceno, 17.07.2004. 


\section{Revista Eletrônica Espaço Teológico ISSN 2177-952X. Vol. 12, n. 22, jul/dez, 2018, p. 54-62}

3.1. O "corpo" e a "cabeça" separados e unidos estão a nos indicar que a Igreja Corpo de Cristo, que tem Cristo como sua cabeça, é um mistério de unidade na diversidade que tem no primado petrino um sinal visível de comunhão. No mistério que envolve a "cabeça" e o "corpo" de Nossa Senhora Aparecida, podemos perscrutar o mistério da unidade do Corpo de Cristo e como o primado petrino na Igreja pode exercer um carisma de unidade inspirado na Mãe do Senhor.

3.2. O diadema do rosto com três broches lembra-nos imediatamente a comunhão trinitária, onde a Igreja se origina, se estrutura e para a qual orienta o seu caminho. A Igreja presente no mundo é chamada a ser expressão visível da comunhão que une o Pai e o Filho e o Espírito Santo e que convida a cada homem, pela porta do Batismo, a ingressar como participante da vida divina.

3.3. O rosto contemplativo de Maria, os olhos fechados e as mãos postas em atitude de oração, estão a nos indicar a necessidade da oração como meio para estar em comunhão com Deus, com a Igreja e com os irmãos. Recordando o incidente lamentável ocorrido dois anos antes de sua visita ao Santuário Nacional, o atentado de 1978 que despedaçou a imagem de Nossa Senhora Aparecida em dezenas de fragmentos, o Papa João Paulo II disse que,

O fato vale como um símbolo: as mãos postas de Maria no meio das ruínas são um convite a seus filhos a darem espaço em suas vidas à oração, ao absoluto de Deus, sem o qual tudo o mais perde sentido, valor e eficácia. $\mathrm{O}$ verdadeiro filho de Maria é um cristão que reza ${ }^{16}$.

3.4. Os lábios sorridentes de Maria parecem querer dizer algo a cada um de nós. Esta alegria que brota discreta dos lábios da Virgem é a alegria do Evangelho que nasce do encontro com Jesus, que é capaz de dissipar a tristeza, o vazio, o desalento e provocar uma existência repleta de sentido. É preciso recuperar a alegria de evangelizar (cf. EN, 80). A evangelização não é apenas mais uma atividade da Igreja, mas o fundamento da missão da Igreja. A causa missionária é a primeira de todas, "é o paradigma de toda a obra da Igreja" (EG, 15). Além disso, o nosso continente latino-americano experimentou desde o primeiro instante da sua evangelização a presença maternal de Maria.

3.5. A lua crescente que está sob os seus pés é um sinal do mysterium lunae da Igreja que tendo a luz de Cristo refletida na sua face, deseja ardentemente iluminar a todos os homens com a proclamação da Boa Nova (cf. LG, 1) na noite escura que atravessa a história humana. O mysterium lunae, que é um símbolo eclesiológico antigo muito querido aos Santos Padres, reflete o itinerário da Igreja na condição de peregrina que caminha neste mundo: ela cai, se levanta, mas nunca desaparece, pois como a "mulher apocalíptica" com a lua debaixo dos pés, a Igreja está para além das vicissitudes históricas, indicando a sua eternidade no tempo e a sua presença entre o céu e a terra.

Assim, deste modo, na imagem de Nossa Senhora da Conceição Aparecida, tão simples e discreta no seu tamanho, nas suas formas até um pouco rudes e toscas, na sua cor de barro

16 JOÃO PAULO II. Homilia na Basílica de Aparecida, 04.07.1980. 


\section{Revista Eletrônica Espaço Teológico ISSN 2177-952X. Vol. 12, n. 22, jul/dez, 2018, p. 54-62}

como se fosse queimada pelo sol (cf. Ct 1,6), com a lua sob os seus pés (cf. Ap 12,1) podemos contemplar nesta perspectiva o mistério de unidade da Igreja (corpo e cabeça) que nasce da comunhão trinitária (diadema na fronte), nutre-se através da oração pessoal-contemplativa (olhos fechados) e da oração comunitário-litúrgica (mãos postas), cresce com o anúncio alegre do Evangelho (lábios sorridentes) e resplandece para todos os povos a luz de Cristo (lua sob os pés).

\section{CONCLUSÃO}

Pelas circunstâncias do encontro prodigioso da imagem, irrompeu no Brasil uma hierofania sem visões nem palavras que, apesar da sua simplicidade, carrega a densidade do Mistério que exige duas posturas próprias dos pescadores que a encontraram: contemplação e acolhida.

Os pescadores, após o primeiro e o segundo lanço de rede, assim que encontraram a imagem de Nossa Senhora da Conceição, após tantas tentativas frustradas para conseguir algum peixe, ao contemplar aquela imagem maltratada e quebrada, não obstante a sua simplicidade, rudeza, pequenez e morenice, reconheceram imediatamente: "É a Virgem da Conceição!". E desde aquele dia, há trezentos anos, são milhares de pessoas que da casa dos humildes pescadores até a monumental Basílica, vão à Aparecida para contemplar a sua imagem e se deixar "ver" pela Senhora.

Quando a recolheram das suas redes, primeiro o corpo e depois a cabeça, viram a imagem da Imaculada Conceição, uma devoção já muito antiga, mas logo perceberam a novidade: uma imagem pequenina, machucada, enegrecida, de traços simples, tosca e frágil. Mas apesar de sua pequenez, "os pescadores não desprezam o mistério encontrado no rio, embora seja um mistério que aparece incompleto. Não jogam fora os pedaços do mistério" e, assim, eles a "agasalham: revestem o mistério da Virgem pescada", "trazem para casa o mistério"17, porque tocaram com suas mãos o "sagrado". A artista plástica Maria Helena Chartuni, depois de restaurar a imagem de Nossa Senhora Aparecida, após o atentado de 1978, relatou que, quando viu aquela multidão no vão do MASP (Museu de Arte de São Paulo) aguardando ansiosa para rever a imagem restaurada, confessou que, "Pela primeira vez a comoção me invadiu e percebi que havia tocado em algo sagrado"18.

Da perspectiva iconográfica ao significado eclesiológico, da imagem à mensagem, Nossa Senhora Aparecida, além de possuir as características de uma imagem sacra e religiosa, de culto e devoção, que carrega a memória de um povo e o significado da existência humana, comunica através da sua simplicidade, na sua relação entre forma e conteúdo, a linguagem do Mistério, integrando o modelo e a figura da Igreja que encontram na Virgem Maria a sua melhor expressão, pois 'Nela, a Igreja entende sua vocação, seu próprio mistério, e nela encontra seu arquétipo, a imagem ideal daquilo que é chamada a ser"19: Virgem, Servidora, Mãe e Esposa. "Quem venera filialmente Maria, abre para si mesmo novos caminhos para o mistério da Igreja" 20 .

\footnotetext{
${ }^{17}$ FRANCISCO. Encontro com o Episcopado Brasileiro, 27.07.2013.

${ }^{18}$ CHARTUNI, M. H. A história de dois restauros: meu encontro com Nossa Senhora Aparecida, 2016, p. 6.

19 CAVACA, O. "De quem é esta imagem?” (Lc 20,24), 2016, p. 18.

${ }^{20}$ FORTE, B. Maria, a mulher ícone do mistério: ensaio de mariologia simbólico-narrativa 1991, p. 199.
} 
Revista Eletrônica Espaço Teológico ISSN 2177-952X. Vol. 12, n. 22, jul/dez, 2018, p. 54-62

"Aparecida" ainda é um mistério "incompleto", porém pleno a ser descoberto, contemplado e acolhido, compreendido, vivido e celebrado na mente, no coração e na vida de cada brasileiro que, através da devoção mariana do nosso povo, pode redescobrir sua pertença e seu lugar no "Corpo de Cristo" e na "barca de Pedro". Aqui foram apresentadas apenas algumas facetas deste grande mistério que podemos admirar, assim como fizeram os três pescadores ao divisar o olhar com a imagem de Nossa Senhora da Conceição Aparecida, esta "mulher" que se tornou um sinal para os tempos e para a história, um guia no itinerário da fé, uma bênção para o nosso povo, um ícone de esperança que nos aproxima do mistério esponsal de Cristo e da Igreja.

\section{BIBLIOGRAFIA}

BIBLIA. A Bíblia de Jerusalém. São Paulo: Paulus, 2006.

BRUSTOLONI, Júlio J. História de Nossa Senhora da Conceição Aparecida: a Imagem, o Santuário e as Romarias - 10 ed. rev. e ampl. - Aparecida, SP: Editora Santuário, 1998.

CAVACA, Osmar. "De quem é esta imagem?" (Lc 20,24). In: GUIMARÃES, Valdivino (org.). Iconografia de Aparecida: teologia da imagem. São Paulo: Paulus, 2016, pp. 9-22.

CHARTUNI, Maria Helena. A história de dois restauros: meu encontro com Nossa Senhora Aparecida. Aparecida, SP: Editora Santuário, 2016.

CONSTITUIÇÃO DOGMÁTIVA LUMEN GENTIUM. Compêndio do Vaticano II.

DOMEZI, M. C. 300 anos de Aparecida: abordagem histórica. O contexto da aparição e a devoção popular. In: Revista de Cultura Teológica, São Paulo, v. 25, n. 90, p. 180, [jul./dez.] 2017.

FORTE, Bruno. Maria, a mulher ícone do mistério: ensaio de mariologia simbóliconarrativa. São Paulo: Paulinas, 1991.

FRANCISCO. Exortação Apostólica Evangelii Gaudium. São Paulo: Paulinas, 2013. . Palavras do Papa Francisco no Brasil. São Paulo: Paulinas, 2013.

IWASHITA, Pedro. Maria e Iemanjá: análise de um sincretismo, São Paulo, Paulinas, 1991. JOÃO PAUlO II. A palavra de João Paulo II no Brasil: discursos e homilias. São Paulo: Paulinas, 1980.

Carta do Papa João Paulo II por ocasião do centenário da coroação de Nossa Senhora Aparecida. Disponível em: < https $/ /$ w2.vatican.va/content/john-paulii/pt/letters/2004/documents/hf_jp-ii_let_20040717_aparecida.html>. Acesso em: 21 mai. 2018.

LAURENTIN, René. Aparições. In: FIORES, Stefano de; MEO, Salvatore (Orgs.). Dicionário de Mariologia. São Paulo: Paulus, 1995, pp. 113-124.

MURAD, Afonso. Visões e Aparições: Deus continua falando?. Petrópolis: Vozes, 1997. PAULO VI. Exortação Apostólica Evangelii Nuntiandi. São Paulo: Paulinas, 1977. .Exortação Apostólica Gaudete in Domino. São Paulo: Paulinas, 1975. .Exortação Apostólica Marialis cultus. Disponível em: < http://w2.vatican.va/content/paul-vi/pt/apost_exhortations/documents/hf_pvi_exh_19740202_marialis-cultus.html>. Acesso em: 21 mai. 2018. 


\section{REVELETEO}

Revista Eletrônica Espaço Teológico ISSN 2177-952X. Vol. 12, n. 22, jul/dez, 2018, p. 54-62

.Letras Apostólicas do Santo Padre Paulo VI. In: SANTUÁRIO Nacional de Nossa Senhora Aparecida. Jubileu de Ouro e Rosa de Ouro. São Paulo. Aparecida: "Santuário de Aparecida", 1970.

RAHNER, Hugo. María y la Iglesia: diez capítulos sobre la vida espiritual. Bilbao: Editorial El Mensajero del Corazón de Jesús, 1958.

RIBEIRO NETO, Pedro A. de Oliveira. A imagem de N. Senhora Aparecida. In: SANTUÁRIO Nacional de Nossa Senhora Aparecida. Jubileu de Ouro \& Rosa de Ouro. Aparecida: Editora Santuário, 1970.

SILVA, Rafael Maria Francisco da. Guadalupe - Aparecida - Lourdes: três mariofanias, uma mesma mensagem. Santo André: Mensageiro de Santo Antônio, 2014.

Recebido em: 23/05/2018

Aprovado em: 08/12/2018 